the level of tertiary or of quaternary structure, that is to say by intra- or inter-chain cross-links.

\section{LEAF MICROFLORA \\ Disense Control}

from a Correspondent

FACTORS which influence the ecology of microorganisms on leaf surfaces were considered at a meeting of the Pesticides Group of the Society of Chemical Industry held on January 15 under the chairmanship of Dr E. Evans (Chesterford Park Research Station). The interrelationship of these factors in relation to practical disease control was indicated by several of the speakers.

The nature of the leaf surface and its microclimate may determine the success or failure of organisms to colonize foliage and these factors were surveyed by Dr B. E. Juniper (University of Oxford) and Dr S. W. Burrage (Wye College, University of London), respectively. Dr Juniper's electron micrographs of the leaf surfaces showed the marked variation in thickness and nature of cuticles and epicuticular waxes, not only between species but also between abaxial and adaxial surfaces of individual leaves. The wettability of leaf surfaces is influenced by the fine structure and chemical composition of the wax. Dr Burrage stated that the temperature and humidity at the leaf surface are determined by the balance between heat transfer by radiation, conduction and evaporation/condensation of water. The shape, size, orientation and surface topography of the individual leaf influence the boundary layer thickness and hence the energy exchange and microclimate.

The effect of the latter on spore germination and the growth of leaf microorganisms was also stressed by Dr J. P. Blakeman (University of Aberdeen). Water on foliage can release substances from leaves, especially older ones that have lost wax by weathering, and from microorganisms. He mentioned that pollen deposits on leaves stimulate spore germination and growth of Botrytis cinerea and of the saprophytic bacterium Sporobolomyces pararoseus. The latter reduced development of Phoma betae lesions on sugar beet foliage, probably by competing for nutrients.

Dr P. J. W. Saunders (University of Manchester) discussed the effects which pollutants may have on leaf surface microflora; for example, Dilocarpon rosae, which is sensitive to sulphur dioxide, will be favoured by a reduction of this pollutant as indicated by the increasing incidence of rose black spot in some areas where clean air zones have been enforced. Dr C. $\mathrm{H}$. Dickinson (University of Newcastle upon Tyne) stated that bacterial populations on foliage usually increase as leaves age. He summarized the effects of various fungicides on microflora on the surfaces of potato and barley leaves. Disturbance of the ecological system by the interactions of fungicide with different microorganisms might produce beneficial or adverse effects on the plant. One fungicide, which decreases populations of saprophytic organisms on the leaf surface, was associated with delayed foliar senescence and increased barley yields even in the absence of recognized pathogens. Dr R. T. Burchill reviewed work at East Malling Research Station showing that apple scab, caused by Venturia inaequalis, can be controlled by spraying orchards with a 5 per cent solution of urea after harvest but before leaf fall. He stated that the mode of action of urea is complex: it may act partly by increasing leaf populations of fungi such as Alternaria spp., Cladosporium spp. and Fusarium spp., all of which antagonize the development of $V$. inaequalis perithecia; moreover, urea stimulates some soil flora and increases the rate of decomposition of fallen leaves, thus decreasing the carryover to the next season of infection by perithecia.

Dr G. Barnes (Chesterford Park Research Station) has investigated the interaction of Erysiphe polygoni and $B$. cinerea on detached leaves of clover, Trifolium pratense. Dry conidia of $B$. cinerea, when placed on the leaf surface 24 hours before inoculating with $E$. polygoni conidia, slightly de- creased germination and formation of the appressorium in the latter and reduced the production of secondary hyphae by as much as 80 per cent. No such effects occurred when conidia of $E$. polygoni were inoculated either before or simultaneously with $B$. cinerea conidia. Interactions between bacterial populations on leaf surfaces were surveyed by $\mathrm{Dr}$ J. E. Crosse (East Malling Research Station). $\mathrm{He}$ has found that inoculation of apple shoots with Erwinia amylovora, the bacterium causing fireblight, immediately after inoculation with a yellow bacterium, which is commonly associated with fireblight lesions, decreased infection by $E$. amylovora. Similarly, the rate of infection and spread of cherry canker, caused by Pseudomonas morsprunorum, is diminished by a white bacterium isolated from cherry leaf surfaces. Attempts to use saprophytic bacteria as a satisfactory biological control against these diseases have, so far, failed because their populations rapidly fall to levels non-competitive with the pathogens.

\section{SUPERFLUIDS}

\section{Building Up the Case}

from a Correspondent

IT now seems much more probable that there is a third superfluid in nature, in addition to liquid ${ }^{4} \mathrm{He}$ and the electron gas in superconductors. This is the implication of a recent report by Webb, Greytak, Johnson and Wheatley (Phys. Rev. Lett., 30, 210; 1973), the latest in a series of papers from both

\title{
DNA Polymerase Mutant of the Smut Fungus
}

SinCE the isolation by DeLucia and Cairns of mutant strains of Escherichia coli lacking DNA polymerase I activity two other DNA polymerases of $E$. coli have been identified and characterization of the biochemistry of DNA replication continues apace. Of course, it should be possible to make essentially similar analyses of the DNA replication machinery of at least some eukaryotes, and with this aim in mind Jeggo et al. screened several hundred tempera. ture sensitive mutants of the smut fungus Ustilago maydis. As they report in Nature New Biology next Wednesday (March 7), they found five temperature sensitive mutants of $U$. maydis that were blocked in DNA synthesis at the non-permissive temperature.

DNA polymerase activity in extracts of one of these mutants was only 1025 per cent that of wild type. Tetrad analyses indicated that the temperature sensitive phenotype of this mutant is the result of a single recessive mutation which may well be in a structural gene for a DNA polymerase because partially purified enzyme from the mutant proved to be more thermolabile than wild type enzyme. Susceptibility to radiation damage and to chemical mutagens of the mutant strain of $U$. maydis growing at different temperatures suggests that the mutation does not affect a principal DNA repair pathway. Because, however, the mutant cells, grown at the non-permissive temperature, develop into filamentous uninucleate forms whereas wild type cells grow by budding like a yeast, it may well be that Jeggo et al. have been lucky and have isolated a temperature sensitive mutation which affects DNA polymerase involved in chromosome replication.

Confirmation of this possibility will depend on the results of experiments which may lead to a characterization of the replication machinery in this fungus. 